\title{
Child Immunization and Vitamin A Supplementation in the District of Bankura, West Bengal
}

\author{
Nirmal Kumar Mandal', Banamali Sinhamahapatra², Nirmalya Sinha², \\ Dipta Kanti Mukhopadhyay², Rama Das ${ }^{2}$, Akhil Bandhu Biswas ${ }^{3}$ \\ ${ }^{1}$ N.R.S. Medical College, Kolkata. ${ }^{2}$ Department of Community Medicine, B.S. Medical College, Bankura. \\ ${ }^{3}$ Institute of Health and Family Welfare, Kolkata
}

\section{A B STR A C T}

\begin{abstract}
Background: District Health Authority of Bankura in the state of West Bengal desired to estimate the coverage of childhood vaccination and vitamin A prophylaxis by an independent body. To address these issues the present study was undertaken. Objectives: To estimate immunization coverage and vitamin A supplementation in 12-23 months children. Methods: A Cross sectional observational study was conducted in the district of Bankura, West Bengal among children aged between 12-23 months with sample size 320 . Study variables were sex, residence, antigen-wise immunization coverage, proportion of fully immunized children, immunization drop-out rate, Vitamin-A (first dose) supplementation etc. Coverage was estimated by proportions and Chi-square $\left(\chi^{2}\right)$ was applied as a test of significance. Results: $99.0 \%, 94.8 \%$ and $91.4 \%$ of studied children received BCG, DPT-3/OPV-3 and Measles vaccination respectively. $80.3 \%$ of children $(80.9 \%$ male and $79.7 \%$ of female) were fully immunized. The drop out rate for highest covered antigen dose (DPT1/OPV1) to lowest covered antigen dose (measles) was $8.1 \%$. Fully immunized children were found more in rural area $(81.7 \%)$ than the urban area (62.5) of the district. Difference was statistically significant. Almost $92 \%$ children received first dose of Vitamin-A. Conclusion: Immunization coverage of Bankura district was higher than that of the state and national figures. Rural coverage is better than urban.
\end{abstract}

Key words: BCG, DPT, OPV, Measles, Immunization coverage, Vitamin A supplementation

\section{INTRODUCTION}

Immunization is an important and cost-effective public health tool for disease prevention and control. Immunization programme aims at reducing mortality and morbidity due to vaccine preventable diseases (VPDs). The Expanded Programme on Immunization was launched in India in 1978 to control VPDs. Subsequently, the programme was renamed as Universal Immunization Programme in 1985 to achieve and sustain universal immunization coverage in infants with three doses of DPT and OPV and one dose each of measles vaccine and BCG. ${ }^{1}$ Rapid household surveys performed in 260 districts in 1998-99 and again in 2002-03 showed that full immunization rates have decreased in 176 (76\%) districts. ${ }^{2}$ UNICEF MCIS survey in 2001-2002

Address for correspondence:

Mobile: 9433390288;

E-mail: nirmalbrp@yahoo.co.in

DOI: 10.5530/ijmedph.3.2011.5 showed that on an average, $35 \%$ of infants in each state were not fully immunized. ${ }^{3}$ In National Family Health Survey (NHHS) -3 , it was revealed that less than $44 \%$ of children 12-23 months were fully vaccinated against 6 major childhood illness. Between the $1^{\text {st }}$ and $3^{\text {rd }}$ doses, drop out rate for DPT was $27 \%$ and that of polio was $16 \%{ }^{4}$ Vitamin A deficiency is found to be maximum between the ages of 6 months to 3 years. Supplementation with Vitamin A in oil was, therefore, recommended to be started at 9 months along with measles vaccine. ${ }^{5}$ NFHS-3 showed that $36.4 \%$ of children aged between 12-17 months received Vitamin-A supplementation in last 6 months. ${ }^{4}$ District of Bankura has paucity of data on various indicators including childhood immunization and vitamin-A coverage. District Health Authority of Bankura desired to estimate the coverage of childhood vaccination and vitamin A prophylaxis by an independent body, which will help them to corroborate with the findings available in routine reporting system, and make decision to appropriately use scarce resources in priority areas of maternal and child health. To address these issues the present study was undertaken. 


\section{MATERIALS AND METHODS}

District of Bankura is situated $225 \mathrm{KM}$ away from Kolkata having a population of 3.19 million in 22 blocks and three municipal areas.

\section{Type of study}

Cross sectional observational

\section{Setting}

District of Bankura, West Bengal

\section{Study subjects}

Children of 12-23 months of age. Mothers of the children were interviewed. In case of mothers' absence, responsible care givers in the family were the respondents.

\section{Sample size}

Considering 95\% confidence limit, 44\% immunization coverage (fully immunized) as per NFHS-III, $8 \%$ allowable error and design effect 2; estimated sample size becomes 296. It is rounded to 320 for equal sub-sample from each of 40 clusters.

\section{Sampling technique}

Revised 40 cluster sampling technique adopted by UNICEF ${ }^{6}$

\section{Ethical issue}

The research protocol was approved by Institutional Ethical Committee of B S Medical College, Bankura and informed consent obtained from each subject prior to inclusion in the study

\section{Procedure}

From village and ward list available with district authority of Bankura, a sampling frame was developed. Based on PPS cluster sampling method, 40 clusters which included three municipal wards and thirty-seven villages, were identified. With the help of community mobilizers/local guides, investigators divided each cluster into four quadrants. With a random start in each quadrant, adjacent houses were visited until required sample i.e. two children between 12-23 months were recruited for the study. Thus a total of at least eight children of 12-23 months age were covered in each of the 40 clusters. Mothers, in both the cases, were interviewed with a pre-designed, pre-tested proforma. If mothers were absent, information was collected from responsible care-givers.

Survey was carried out from $17^{\text {th }}$ June, 2008 to $6^{\text {th }}$ July, 2008. The survey coordinator supervised more than $20 \%$ of clusters and consistency check was done by surveying more than $20 \%$ of the surveyed households. Data was verified by scrutinizing more than $10 \%$ of the survey questionnaire by the coordinator himself before dispatching for computer entry and analysis.

\section{Data analysis}

Data were analyzed in MS Excel. Proportions were calculated. Stat Calc of Epi Info: version 3.4.1 was used to calculate Chi-square $\left(\chi^{2}\right)$ as a test of significance. Yates correction was made where applicable.

\section{RESULTS}

Universal immunization of children against six vaccine preventable diseases (namely Tuberculosis, Diphtheria, Whooping Cough, Tetanus, Poliomyelitis and Measles) is crucial in reducing infant and child mortality. According to the immunization schedule outlined by Govt. of India and WHO, all primary vaccination, including measles should be administered by the time a child is 12 months old. First dose of vitamin A supplementation is recommended at 9 months along with measles vaccine. A total of 324 children (Male152 and Female-172) in the age group of 12-23 months were covered in the survey. Mean age of the surveyed children was 17.7 months (SD-3.52 months).

Immunization card was available and present in $94.8 \%$ of the surveyed children. Availability was slightly more among male $(95.4 \%)$ than female $(94.2 \%)$ and rural $(95.3 \%)$ than urban children $(87.5 \%)$ (Table 1$)$.

Antigen-wise coverage for BCG, DPT-3/OPV-3 and Measles were $99.0 \%, 94.8 \%$ and $91.4 \%$ respectively. $43.93 \%$ received BCG at birth (within 2 weeks of delivery). Mean age of BCG vaccination was 3.84 weeks with SD-3 weeks. Average age of initiation of OPV-1/DPT-1 was found to be 8.1 weeks. The average age of completion of $3^{\text {rd }}$ dose of DPT/OPV and primary immunization was found to be 4.90 months and 9.94 months respectively. No statistical difference was found between male and female with respect to BCG, DPT3/OPV3 and measles vaccine coverage, but when analyzed by residence, it was found that immunization coverage of rural children (BCG-99.7\%, DPT3/OPV3$96 \%$ and measles-93\%) were significantly more than their counterpart in urban area (BCG-91.7\%, DPT3/OPV3$79.2 \%$ and measles- $70.8 \%$ ) (Table 1)

The present study revealed that $80.3 \%$ of children $(80.9 \%$ male and $79.7 \%$ of female) were fully immunized (BCG, Measles and three doses each of DPT and OPV at 4 weeks interval excluding OPV-0) by first year of life. 19.4\% of children were partially immunized and only one female child was found to be non-immunized. Fully immunized children were found more in rural area $(81.7 \%)$ than the urban area (62.5) of the district. Difference was statistically significant $(p-0.02)$. (Table 2$)$ 


\begin{tabular}{|c|c|c|c|c|c|c|c|c|c|c|}
\hline \multirow[t]{2}{*}{ Attribute } & \multirow{2}{*}{$\begin{array}{l}\text { Immu } \\
\text { card }\end{array}$} & \multicolumn{9}{|c|}{ Immunization and Vitamin-A ( $1^{\text {st }}$ dose) coverage } \\
\hline & & BCG & DPT-1 & DPT-2 & DPT-3 & OPV-1 & OPV-2 & OPV-3 & Measles & Vit-A \\
\hline $\begin{array}{l}\text { Male } \\
\mathrm{N}=152\end{array}$ & $\begin{array}{c}145 \\
(95.4)\end{array}$ & $\begin{array}{c}151 \\
(99.3)\end{array}$ & $\begin{array}{c}151 \\
(99.3)\end{array}$ & $\begin{array}{c}150 \\
(98.7)\end{array}$ & $\begin{array}{c}144 \\
(94.7)\end{array}$ & $\begin{array}{c}151 \\
(99.3)\end{array}$ & $\begin{array}{c}150 \\
(98.7)\end{array}$ & $\begin{array}{c}144 \\
(94.7)\end{array}$ & $\begin{array}{c}139 \\
(91.5)\end{array}$ & $\begin{array}{c}140 \\
(92.1)\end{array}$ \\
\hline $\begin{array}{l}\text { Female } \\
\mathrm{N}=172\end{array}$ & $\begin{array}{c}162 \\
(94.2)\end{array}$ & $\begin{array}{c}170 \\
(98.8)\end{array}$ & $\begin{array}{c}171 \\
(99.4)\end{array}$ & $\begin{array}{c}169 \\
(98.3)\end{array}$ & $\begin{array}{c}163 \\
(94.8)\end{array}$ & $\begin{array}{c}171 \\
(99.4)\end{array}$ & $\begin{array}{c}169 \\
(98.3)\end{array}$ & $\begin{array}{c}163 \\
(94.8)\end{array}$ & $\begin{array}{c}157 \\
(91.3)\end{array}$ & $\begin{array}{c}158 \\
(91.9)\end{array}$ \\
\hline $\begin{array}{l}\chi^{2} \\
p\end{array}$ & $\begin{array}{l}0.24 \\
0.63\end{array}$ & $\begin{array}{l}0.01 \\
0.91\end{array}$ & $\begin{array}{l}0.39 \\
0.53\end{array}$ & $\begin{array}{l}0.02 \\
0.89\end{array}$ & $\begin{array}{l}0.06 \\
0.81\end{array}$ & $\begin{array}{l}0.39 \\
0.53\end{array}$ & $\begin{array}{l}0.02 \\
0.89\end{array}$ & $\begin{array}{l}0.06 \\
0.81\end{array}$ & $\begin{array}{l}0.02 \\
0.88\end{array}$ & $\begin{array}{l}0.02 \\
0.90\end{array}$ \\
\hline $\begin{array}{l}\text { Urban } \\
N=24\end{array}$ & $\begin{array}{c}21 \\
(87.5)\end{array}$ & $\begin{array}{c}22 \\
(91.7)\end{array}$ & $\begin{array}{c}23 \\
(95.8)\end{array}$ & $\begin{array}{c}22 \\
(91.7)\end{array}$ & $\begin{array}{c}19 \\
(79.2)\end{array}$ & $\begin{array}{c}23 \\
(95.8)\end{array}$ & $\begin{array}{c}22 \\
(91.7)\end{array}$ & $\begin{array}{c}19 \\
(79.2)\end{array}$ & $\begin{array}{c}17 \\
(70.8)\end{array}$ & $\begin{array}{c}20 \\
(83.3)\end{array}$ \\
\hline $\begin{array}{l}\text { Rural } \\
N=300\end{array}$ & $\begin{array}{c}286 \\
(95.3)\end{array}$ & $\begin{array}{c}299 \\
(99.7)\end{array}$ & $\begin{array}{c}299 \\
(99.7)\end{array}$ & $\begin{array}{c}297 \\
(99.0)\end{array}$ & $\begin{array}{c}288 \\
(96.0)\end{array}$ & $\begin{array}{c}299 \\
(99.7)\end{array}$ & $\begin{array}{c}297 \\
(99.0)\end{array}$ & $\begin{array}{c}288 \\
(96.0)\end{array}$ & $\begin{array}{c}279 \\
(93.0)\end{array}$ & $\begin{array}{c}278 \\
(92.7)\end{array}$ \\
\hline $\begin{array}{l}\chi^{2} \\
P\end{array}$ & $\begin{array}{l}1.39 \\
0.23\end{array}$ & $\begin{array}{l}8.01 \\
0.005\end{array}$ & $\begin{array}{l}0.91 \\
0.34\end{array}$ & $\begin{array}{l}3.78 \\
0.05\end{array}$ & $\begin{array}{c}9.51 \\
0.002\end{array}$ & $\begin{array}{l}0.91 \\
0.34\end{array}$ & $\begin{array}{l}3.78 \\
0.05\end{array}$ & $\begin{array}{c}9.51 \\
0.002\end{array}$ & $\begin{array}{l}11.17 \\
0.0008\end{array}$ & $\begin{array}{l}1.51 \\
0.22\end{array}$ \\
\hline $\begin{array}{l}\text { Total } \\
\mathrm{N}=324\end{array}$ & $\begin{array}{c}307 \\
(94.8)\end{array}$ & $\begin{array}{c}321 \\
(99.0)\end{array}$ & $\begin{array}{c}322 \\
(99.4)\end{array}$ & $\begin{array}{c}319 \\
(98.5)\end{array}$ & $\begin{array}{c}307 \\
(94.8)\end{array}$ & $\begin{array}{c}322 \\
(99.4)\end{array}$ & $\begin{array}{c}319 \\
(98.5)\end{array}$ & $\begin{array}{c}307 \\
(94.8)\end{array}$ & $\begin{array}{c}296 \\
(91.4)\end{array}$ & $\begin{array}{c}298 \\
(92.0)\end{array}$ \\
\hline
\end{tabular}

N.B: Figures in the parenthesis indicates Percentages

\begin{tabular}{|c|c|c|c|}
\hline \multirow[t]{2}{*}{ Attribute } & \multicolumn{3}{|c|}{ Immunization coverage } \\
\hline & $\begin{array}{c}\text { Fully } \\
\text { immunized }\end{array}$ & $\begin{array}{c}\text { Partially } \\
\text { immunized }\end{array}$ & Non-immunized \\
\hline $\begin{array}{l}\text { Male } \\
N=152\end{array}$ & $123(80.9)$ & $29(19.1)$ & $0(0.0)$ \\
\hline $\begin{array}{l}\text { Female } \\
\mathrm{N}=172\end{array}$ & $137(79.7)$ & $34(19.8)$ & $1(0.6)$ \\
\hline $\begin{array}{l}\chi^{2} \\
p\end{array}$ & $\begin{array}{l}0.02 \\
0.88\end{array}$ & & \\
\hline $\begin{array}{l}\text { Urban } \\
N=24\end{array}$ & $15(62.5)$ & $8(33.3)$ & $1(4.2)$ \\
\hline $\begin{array}{l}\text { Rural } \\
N=300\end{array}$ & $245(81.7)$ & $55(18.3)$ & $0(0.0)$ \\
\hline $\begin{array}{l}\chi^{2} \\
P\end{array}$ & $\begin{array}{l}5.15 \\
0.02\end{array}$ & & \\
\hline $\begin{array}{l}\text { Total } \\
N=324\end{array}$ & $260(80.3)$ & $63(19.4)$ & $01(0.3)$ \\
\hline
\end{tabular}

Figure in column 3 and 4 merged to compute $\chi^{2}$

N.B: Figures in the parenthesis indicates Percentages

The drop out rate for both DPT-1 to DPT-3 and OPV-1 to OPV-3 was $4.7 \%$. The drop out rate for highest covered antigen dose (DPT1/OPV1) to lowest covered antigen dose (measles) was $8.1 \%$. Sex-wise analysis of drop-outs rate of different vaccines showed no significant differences. Drop-out rates of urban children with respect to DPT1/ OPV1 to DPT3/OPV3 and HCAD to LCAD $(17.4 \%$ and $26.1 \%)$ were found to be more than rural children $(3.7 \%$ and $6.7 \%$ ). (Table 3 )

Most of the children (96.9\%) took immunization from existing Government health facilities. 81\% took it from sub-centers.

\begin{tabular}{lcc} 
Table 3: Drop-out Rates of Different Vaccines & \\
\hline \multicolumn{1}{c}{ Attribute } & $\begin{array}{c}\text { DPT-1/OPV-1 to } \\
\text { DPT-3/OPV-3 }\end{array}$ & $\begin{array}{c}\text { HCAD to } \\
\text { LCAD }\end{array}$ \\
\hline Male & $7(4.6)$ & $12(7.9)$ \\
DPT-1/OPV-1-151 & & \\
Female & $8(4.7)$ & $14(8.2)$ \\
DPT-1/OPV-1-171 & & 0.01 \\
$\chi^{2}$ & 0.06 & 0.9 \\
p & 0.8 & $6(26.1)$ \\
Urban & $4(17.4)$ & $20(6.7)$ \\
DPT-1/OPV-1-23 & & \\
Rural & $11(3.7)$ & 8.37 \\
DPT-1/OPV-1-299 & & 0.004 \\
$\chi^{2}$ & 6.22 & $26(8.1)$ \\
P & 0.01 & \\
Total & $15(4.7)$ & \\
DPT-1/OPV-1-322 & & \\
\hline N.B: Figures in the parenthesis indicates Percentages &
\end{tabular}

The major reasons for partially/non-immunized by first year of life was found to be un aware of need to return for subsequent doses (37.5\%), child ill, not brought (29.7\%) unaware for need for immunization $(18.7 \%)$, measles given earlier than the stipulated period i.e. 270 days (12.5\%), Mother too busy/Mother ill (9.4\%), postponed till another time $(6.2 \%)$, child ill, brought but not given vaccine $(6.2 \%)$ etc. (Table 4$)$

Almost 92\% children aged between 12 to 23 months received first dose of Vitamin-A. 86.4\% received first dose along with measles vaccine. The coverage was found to be more or less same in both sexes. Vitamin $\left(1^{\text {st }}\right.$ dose $)$ coverage was found to be more in rural children $(92.7 \%)$ than in urban children $(83.3 \%)$, but the difference was not significant. (Table 1) 
Table 4: Causes of Partial/Non-immunization ${ }^{* \star}$

\begin{tabular}{lc}
\hline \multicolumn{1}{c}{ Causes } & Number (\%) \\
\hline Unaware of need for immunization & $12(18.8)$ \\
Unaware of need to return for subsequent doses & $24(37.5)$ \\
Place and or time of immunization unknown & $02(3.1)$ \\
Fear of adverse reaction & $02(3.1)$ \\
Wrong notions on contradiction & $03(4.7)$ \\
Place to far & $02(3.1)$ \\
Time inconvenient & $03(4.7)$ \\
Mother too busy/Mother ill & $6(9.4)$ \\
Child ill, not brought & $19(29.7)$ \\
Child ill, brought but not given & $04(6.2)$ \\
Postponed till another time & $04(6.2)$ \\
Vaccine not available & $03(4.7)$ \\
Measles vaccine given before 270 days & $08(12.5)$ \\
Gap between OPV-1/DPT-1 and OPV-2/DPT-2 & $03(4.7)$ \\
less than 4 weeks & \\
\hline N.B: Figures in the parenthesis indicates Percentages & $* *$ Multiple responses
\end{tabular}

\section{DISCUSSION}

$94.8 \%$ of the surveyed children in the district of Bankura had their immunization cards. This figure is much higher than the corresponding figures in India (37.5\%) as well as in West Bengal (71.9\%) as observed in NFHS-3. ${ }^{4}$

The present study revealed that $80.3 \%$ of children $(80.9 \%$ male and $79.7 \%$ of female) were fully immunized. According to the documents of NFHS-1, NFHS-2 and NFHS-3, fully immunized children in West Bengal were 34.2\%, 43.8\% and $64.3 \%$ respectively. Respective National figures were $35.5 \%, 42 \%$ and $43.5 \%$ only. ${ }^{4}$ In $2003,53.13 \%$ and $61.56 \%$ of children in same age group were found to be fully immunized in the District of Birbhum and Purba Medinipur respectively. ${ }^{7}$ Fully immunized children in West Bengal was found to be declined from $54.3 \%$ in $1997-98$ to $48.1 \%$ in 1998-99. In the present study no difference was found between immunization coverage rates of male and female children ( $p-0.88)$. In Madhya Pradesh, proportion of fully immunized children was $60.8 \%$ and immunization coverage rates in male and female children were $63.7 \%$ and $57.1 \%$ respectively. Immunization coverage of rural children $(81.7 \%)$ in the District of Bankura was found to be more in comparison with that of urban children $(62.5 \%)$. The difference was statistically significant $(p-0.02)$. Similarly, immunization coverage in 1998-99 in West Bengal (48.1\%), was found to be higher than that of Municipal corporations of Calcutta (47.1\%), Howrah (41.5\%) and Siliguri (29.6\%). ${ }^{8}$ But reverse trend was found in NFHS-3 report, where fully immunized children in rural and urban areas of West Bengal were $62.8 \%$ and $70.3 \%$ respectively. ${ }^{4}$ Same were the trend in Madhya Pradesh, where corresponding rates were $57 \%$ and $66.8 \%$ respectively. In urban slum of Jamnagar city, $75.38 \%$ male and $70 \%$ of female children were fully immunized. ${ }^{10}$
It was revealed that $99.0 \%$ of studied children received BCG vaccination. Antigen wise coverage was found to be 94.8\% for DPT-3/OPV-3 and $91.4 \%$ for Measles vaccination. Antigen-wise coverage of the children in present study was higher than that of West Bengal as observed in NFHS-3 documents for BCG (90.1\%), DPT-3 (71.5\%), OPV-3 $(80.7 \%)$ and Measles $(74.7 \%)$.Increasing trend was found compared with the documents of NFHS- 1 and NFHS-2. ${ }^{4}$ Though there was no differences between antigen-wise immunization coverage among male and female children $(p<0.05)$, but antigen-wise immunization coverage was found higher among rural children (BCG-99.7\%, DPT-3/ OPV-3-96\% and measles-93\%) than their counterpart in urban group(BCG-91.7\%, DPT-3 / OPV-3-79.2\% and measles-70.8\%) and the differences were found to be significant $(\phi<0.01)$. Such rural-urban trend was not found in NFHS-3, where urban group had better immunization coverage both in India and West Bengal. ${ }^{4}$

The drop out rate for both DPT-1 to DPT-3 and OPV-1 to OPV-3 was $4.66 \%$. . It is much less compared with the findings of the study done elsewhere. Drop-out rates with respect to DPT and OPV were $23.4 \%, 13.6 \%, 15.8 \%$ and $32.6 \%$ in West Bengal, Kolkata, Howrah and Siliguri respectively in 1998-99. ${ }^{8}$ Looking into the drop out rates of highest covered antigen dose (DPT-1/OPV-1) to lowest covered antigen dose (measles), it was found that it was almost double (8.07\%). Trend was same in other studies. ${ }^{7,8}$ In Birbhum and Purba Medinipur districts of West Bengal in the year of 2003, the drop out rate of HCAD to LCAD were $33.46 \%$ and $25.93 \%$ respectively. ${ }^{7}$

In the present study, almost $92 \%$ received first dose of Vitamin-A. Coverage was found to be more or less same in both sexes. Vitamin A supplementation was more in rural $(92.7 \%)$ than in urban area $(83.3 \%)$, but difference was not significant $(p-0.22)$. A study carried out in 2006 in Matigara block of Darjeeling district revealed that $65.7 \%$ of children received the $1^{\text {st }}$ dose of vitamin A. ${ }^{11}$ NFHS-3 showed that $36.4 \%$ children aged between 12-17 months in West Bengal received Vitamin-A supplementation in last 6 months. $28.4 \%$ of urban children and $44.4 \%$ of rural children in the age group 12-35 months received Vitamin-A supplementation in last 6 months. ${ }^{4}$ The major reasons, as observed in the present study, for partially/non-immunized by first year of life was unawareness about return for subsequent doses $(37.5 \%)$, child illness $(29.7 \%)$ and unawareness about need for immunization $(18.7 \%)$. In the study conducted in slum area of Jamnagar city, it was found that $80.36 \%$ did not turn up due to ignorance and $14.28 \%$ told about inconvenience. ${ }^{10}$ In another study, conducted in Madhya Pradesh, factors revealed as a cause of non-immunization were lack of information (33.8\%-41.4\%), lack of motivation (19.8\%-31.4\%) and obstacles (30.1\%-36.3\%). ${ }^{9}$ 
It is concluded that immunization coverage of Bankura district was higher than that of the state and national figures. Rural coverage was better than urban. It might be due to better infrastructural facilities, adequate trained manpower and defined catchments areas prevailed in the rural than the urban municipal areas of the district.

\section{ACKNOWLEDGEMENTS}

We wish to convey our sincere thanks to the Chief Medical Officer of Health and District Health and Family Welfare Samity, Bankura for financial support to conduct the study.

\section{REFERENCES}

1. Core Programme Clusters, Family and Community Health, Routine Immunization, WHO, India.

2. Rapid Household Survey $\mathrm{RCH}$ project; International Institute for Population Sciences.
3. UNICEF MCIS survey 2001-2002.

4. National Family Health Survey (NFHS-3), 2005-06, India.

5. National Institute of health and family Welfare, New Delhi, Reproductive and Child Health, Module for Medical Officer (Primary health Centre) MO (PHC),May 2000.

6. Immunization Coverage Cluster Survey-reference Manual; Immunization, Vaccine and Biologicals; WHO, Geneva, Switzerland, 2005.

7. Dasgupta S, Roy Karmakar P, Mandal NIK, Roy RP, Mallik S, Mandal AK. Routine Primary Immunization: Status in Two Districts of West Bengal. Indian Journal of Public Health. 2005; 44(4):223-226.

8. Dasgupta S, Pal D, Sinha RN, Mandal NK, Roy Karmakar P, Saha I et al. Declining trend in routine UIP coverage. Indian Journal of Public Health. 2001; 45(1):20-23.

9. Yadav RJ, Singh P. Immunization status of children and mothers in the state of Madhya Pradesh. Indian journal of Community Medicine. 2004; 24(3):147-148.

10. Jadav S, Mangal S, Padhiyar N, Mehta JP, Yadav BS. Evaluation of immunization coverage in urban slum of Jamnagar City. Indian journal of Community Medicine. 2006; 31(4):300-301.

11. Mukhopadhyay DK, Mandal S, Sadhukhan SK, Chakraborty M, Lahiri SK. Vit A deficiency and coverage under national programme in a subHimalayan rural community of West Bengal using lot quality assurance sampling. Indian J. Prev.Soc.Med. 2007; 38(3 and 4):197-201. 